\title{
Sample Preparation of Ductile Heterogeneity Materials by Ultramicrotomy
}

\author{
Heesu Chae, Hee-Seok Kweon, A-Reum Je, \\ Seok-Hoon Lee, Jin-Gyu Kim* \\ Division of Electron Microscopic Research, Korea Basic \\ Science Institute (KBSI), 169-148 Gwahangno, Yuseong-gu, \\ Daejeon 305-806, Korea
}

(Received February 15, 2012; Revised March 26, 2012;

Accepted March 26, 2012)

\begin{abstract}
For TEM study of biological samples or polymers that are contained in organic structure, it is often required that the sample is prepared by using ultramicrotome and stained with proper agents to increase the contrast of organic structure. In this study, we investigated an efficient TEM sample preparation method for ductile heterogeneity material by using ultramicrotomy. Cryo-ultramicrotomy is a suitable method that is capable of rendering sample hardness for various ductile materials. However, it has several factors to consider, such as experimental cost, working time and finding the optimal staining conditions. To satisfy these considerations, we prepared TEM sample by using ultramicrotome without cryofunction, and secured the sample hardness by applying the staining process prior to ultrathin sectioning. The cross-linked polyethylene structure in the sample was stained with the $2 \% \mathrm{RuO}_{4}$ solution in a sealed test tube for 24 hours at $4^{\circ} \mathrm{C}$. After the sample staining, ultrathin sections of sample were prepared using ultramicrotome. As a result, it was revealed that the difficulties associated with staining of ultrathin sections prepared by low-temperature conditions were improved. In addition, appropriate staining depth of sample could be selected for sectioning process. The quality of TEM sample obtained by using this method was better than that of cryo-ultramicroscopy. Finally, it is expected that our method could be effectively applied in TEM sample preparation for a variety of nano-bio convergence materials. (채희수, 권희석, 제아름, 이석훈, 김진규: 연 성 이종 재료 시료의 상온 절편 제작법)
\end{abstract}

Keywords : Ductile heterogeneity material, Ultramicrotomy, Sample preparation, Transmission electron microscopy

21세기 들어 나노 과학기술이 급부상함에 따라 나노 신소 재를 분석할 수 있는 전자현미경의 중요성이 크게 높아지고
있다. 특히, 무기재료에서 나타나는 다양한 형태의 구조가 제 안되면서 간접적인 방법보다는 명확하고 직접적인 관찰방법 이 더욱 중요하게 되었다. 이러한 무기재료의 미세 구조 관 찰은 광학현미경에서부터 전자현미경까지 다양한 형태의 현 미경을 사용하여 수행되고 있다. 일반적인 저전압 TEM 시편 제작은 투과 빔의 최적 영상을 구현하기 위해서 $100 \mathrm{~nm}$ 이하 두께의 시편을 준비해야 한다. 이러한 나노 크기의 미세 조직 관찰을 위한 시편 제작 방법에는 기계적 연마와 이온 밀러를 통한 방법, 집속이온빔장치(Focus Ion Beam, FIB)를 이용한 방법 그리고 초박절편기 (Ultramicrotome, UT)를 이용한 방법 등이 있다(Ayache et al., 2009).

그 중에서도 금속 재료 시료를 제외한 생물 및 중합체 시 료의 경우 시편의 손상을 최소화하고, 두께 조절이 가능한 초박절편기를 이용한 절편 제작 방법이 주로 사용되고 있 다. 비록 초박절편기를 이용한 방법이 고분자 복합체의 내부 구조형태와 결정구조의 정보를 얻기 위한 적절한 방법이지 만, 고분자 복합체 시료의 $70 \%$ 가량은 시료의 경도가 너무 낮아 상온에서는 절편제작에 어려움이 있다(Sawyer et al., 2008). 이러한 문제를 해결하기 위해 냉각 기능이 장착된 초 박절편기 즉, 동결 초박절편기를 이용하는 방법이 추가적으로 사용되기도 한다. 이러한 동결 초박절편기를 이용하는 방법 또한 절편제작 시 주위 환경과 냉각 기능이 달린 chamber의 온도 차이에 의해 knife와 시료표면에 성애가 생겨 샘플을 제작하는데 어려움이 많기 때문에 시료 제작 과정에서 시료 의 형태와 구조가 변하지 않도록 더욱 세심한 주의가 필수 적이며 (Bozzola \& Russell, 1992), 많은 시간과 비용이 소요 된다는 단점이 있다.

이러한 문제를 극복하고 준비된 고분자 복합체의 절편 시 편은 TEM 영상 콘트라스트를 향상시키기 위해 염색과정을 거쳐야 한다. 염색과정은 녹는점 $\left(T_{m}\right)$ 이 낮은 cis-polyisoprene 을 결정화하고 염색 시약으로 비결정 영역만을 선택적으로 염색함으로써 결정과 비결정 영역의 전자밀도차를 증대시켜 $\mathrm{TEM}$ 이미지의 콘트라스트를 증가시키는 효과가 있다. Table 1 은 대표적인 고분자의 염색 시약의 종류를 나타내고 있다. 일반적으로 수 $\mathrm{nm}$ 이하의 구조는 염색에 의하여 구조가 파

본 연구는 한국기초과학지원연구원의 자체연구과제 (T3221B) 및 지식경제부 신재생에너지기술개발사업의 일환(20113020030020)으로 수행되었습니다.

* Correspondence should be addressed to Dr. Jin-Gyu Kim, Division of Electron Microscopic Research, Korea Basic Science Institute, 169-148 Gwahangno, Yuseonggu, Daejeon 305-806 Korea. Ph.: (042) 865-3961, Fax: (042) 865-3939, E-mail: jjintta @ kbsi.re.kr 
Table 1. Staining agents for various types of polymers

\begin{tabular}{ll}
\hline \multicolumn{1}{c}{ Polymer } & \multicolumn{1}{c}{ Stains } \\
\hline $\begin{array}{l}\text { Unsaturated hydrocarbons, esters, alcohols, amines } \\
\text { Acids, esters }\end{array}$ & $\begin{array}{l}\text { Osmium tetroxide } \\
\text { (a) Hydrazine } \\
\text { (b) Osmium tetroxide }\end{array}$ \\
$\begin{array}{l}\text { Unsaturated rubber (resorcinol formaldehyde-latex) } \\
\text { Amides, esters, PP }\end{array}$ & Ebonite \\
$\begin{array}{l}\text { Saturated hydrocarbons (PE, PP), esters, alcohols, aromatics, amines, rubber, } \\
\text { bisphenol A, styrene }\end{array}$ & Phosphotungstic acid \\
$\begin{array}{l}\text { Esters, aromatic polyamides } \\
\text { Acids, esters }\end{array}$ & Silvenium tetroxide, Chlorosulfonic acid/uranyl acetate \\
\hline
\end{tabular}

괴되는 경우가 많이 있으니 특별한 주의가 필요하다(Chou et al., 2002; Jeong, 2009).

본 연구에서는 상기에서 서술한 고분자복합체의 TEM 연 구에 필수적인 초박절편기룰 이용한 시편 제작에 있어 보 다 편리하고 유용할 수 있는 시편 제작의 기술적인 면을 논 의하고자 하며, 특히 연성 이종 재료가 포함되어 있는 가교 폴리에틸렌 시료에 대해 동결 초박절편기와 상온 초박절편 기로 제작한 절편을 $\mathrm{TEM}$ 을 통하여 비교 분석하였다.

연성 이종 재료 시료인 가교 폴리에틸렌은 우수한 절연 특성 및 기계적 성질로 인해 초고압 케이블의 절연물질로 널리 사용되어지고 있다. 기존 절연물질인 폴리에틸렌에 첨 가제를 첨가함으로써 절연층과 반도전층의 계면의 구조형태 를 제어함으로써 절연 특성을 향상시킬 수 있다고 알려져 있다(Okamoto \& Ishida, 1994; Yoo, 1998). 본 연구에 사용된 가교 폴리에틸렌 시료는 반구형 모양으로 성형한 반도전 전극층과 가운데 부분을 반구형으로 파낸 모양으로 성형한 XLPE 절연층을 접착하여 제작되었다. Fig. 1 과 같이 제작한 후, 반대편 접지전극을 위해 도전성 페인트를 도포하여 시료 를 완성하였다(Shim et al., 2004; Youn et al., 2004).

이 시료를 먼저 두께가 약 $1 \mathrm{~mm}$ 가 되도록 절단하고, 시 편을 제작하기 위해 염색이 되지 않은 시료를 면도날을 사 용하여 동결 초박절편기(Ultracut UCT \& EMFCS, Leica, Austria)의 고정홀더에 들어갈 수 있을 정도의 크기와 두께 로 잘라 낸 다음 시료의 단면을 매끄럽게 trimming 한 후 블록을 삭정하였다(Fig. 2a). 블록 삭정 시 블록의 모양은 사 다리꼴로 만들며 이때 아랫변을 절연층으로 해야 한다. 이는 반도전 전극층인 carbon 층보다 절연층인 lamella 층이 더 약 하기 때문에 블록 삭정 시 다이아몬드날의 힘을 더 받게 하 기 위함이다. 이 블록을 다이아몬드날을 이용하여 $-60^{\circ} \mathrm{C}$ 에 서 $100 \mathrm{~nm}$ 두께로 자른 뒤, 200 mesh grid에 올렸다(Fig. 2b). 이 grid를 $0.5 \% \mathrm{RuO}_{4}(\mathrm{EMS}, \mathrm{USA})$ 용액에 담가 $4^{\circ} \mathrm{C}$ 에서 24 시간 동안 염색하였다(Fig. 2c). $\mathrm{RuO}_{4}$ 는 유기용매에 용해되 며, 다양한 유기화합물을 산화시키는데 사용되는 다목적의 산화제로 잘 알려져 있다. $\mathrm{RuO}_{4}$ 는 고분자를 산화시키며

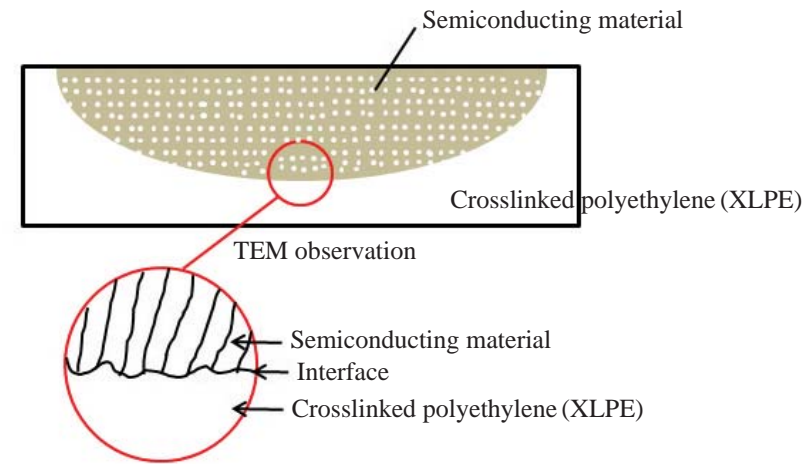

Fig. 1. Cross-sections of the semiconducting interface as observed in a TEM.

$\mathrm{RuO}_{2}$ 로 전환되고 고분자는 carboxylate $(\mathrm{COORu})$ 결합을 통 하여 가교된다. 전환된 $\mathrm{RuO}_{2}$ 는 고분자 내에 침적된다. 또한, $\mathrm{RuO}_{4}$ 는 강한 산화제이므로 유기물질에 대하여 강한 확산, 침투력, 반응성 등을 갖고 있어, 불포화 이중결합을 포함하지 않은 시료의 경우에도 염색이 가능하다(Vitali \& Montani, 1980).

다음 단계로 동결 초박절편기에 의해 제작된 시편과의 비 교를 위해 상온 초박절편기(Ultracut UCT, Leica, Austria)를 이용한 시편제작을 시도하였다. 일반적으로 고분자 복합체 시료의 염색은 염색효과 뿐만 아니라 고정화 효과를 나타내 기도 한다(Kato, 1967). 이러한 이유로 상대적으로 연화점이 낮은 무른 시료의 경우에도 염색을 통한 고정화 효과를 이 용한 동결 초박절편기 대신에 상온 초박절편기를 이용하여 시편제작이 가능할 것이라는 기대에 의한 것이다. 상온 초박 절편기를 이용해 시편을 제작하기 위해서 $2 \% \mathrm{RuO}_{4}$ 용액을 준비하였다. 이 $2 \% \mathrm{RuO}_{4}$ 용액은 분말형태의 $\mathrm{RuO}_{4} 1 \mathrm{~g}$ 을 D.W (distilled water) $50 \mathrm{~mL}$ 에 첨가하여 $50^{\circ} \mathrm{C}$ 에서 희석하여 제조 하였다. 동결 초박절편기로 제작한 절편의 염색에 비해 염색 약의 농도를 증가시킨 이유는 상온 초박절편기 시편의 경우 에는 두께가 약 $1 \mathrm{~mm}$ 인 절편제작 이전의 벌크상태이므로 시료내부까지 염색이 가능하도록 고려되었기 때문이다. Fig. 


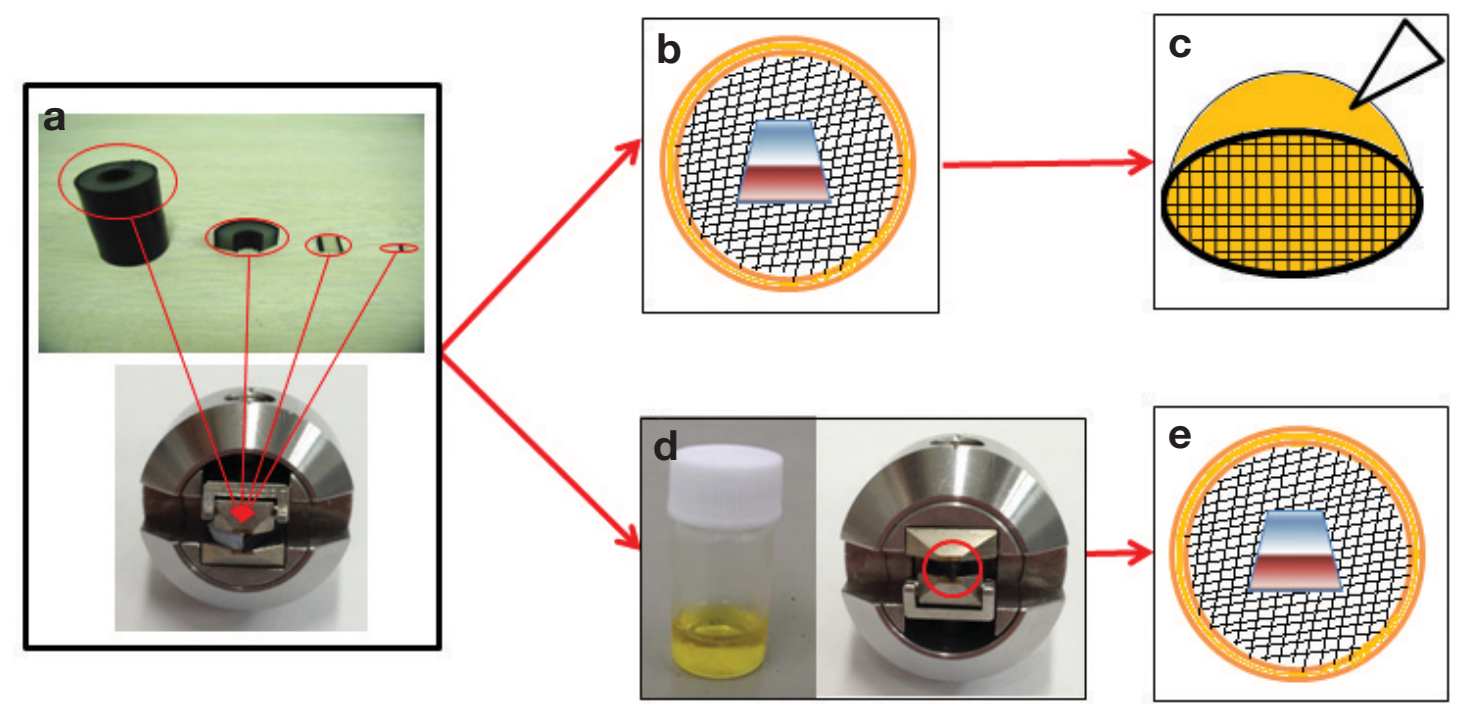

Fig. 2. TEM sample preparation for ductile heterogeneity materials. (a) shows sample cutting and trimming process for ultramicrotomy. (b) and (c) indicate ultrathin sectioning and specimen staining in cryo-ultramicroscopy method, respectively. (d) and (e) indicate sample staining and ultrathin sectioning in ultramicroscopy method, respectively.
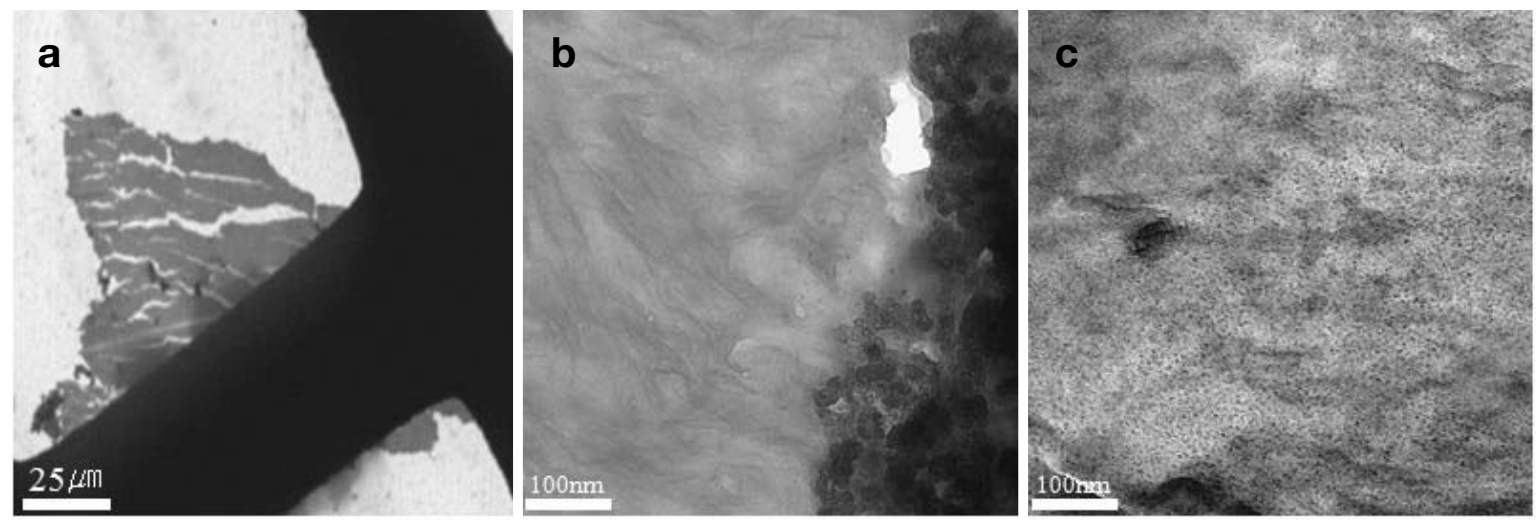

Fig. 3. TEM images of specimen prepared by cryo-ultramicrotomy; (a) overall appearance of a section, (b) interface between semi-conducting and XLPE insulating material, (c) lamellar structure in XLPE insulating material.

2 와 같이 두께 약 $1 \mathrm{~mm}$ 로 절단된 시료 2 3개를 $2 \% \mathrm{RuO}_{4}$ 용액 $1 \mathrm{~mL}$ 가 담긴 유리병에 넣었다. 이 때, 염색 시약에 너 무 많은 시료를 넣게 되면 골고루 염색이 되지 않으므로 주 의하여야 한다. 이 시료를 $4^{\circ} \mathrm{C}$ 에서 24 시간 동안 염색한 후 (Fig. 2d), 증류수로 washing 하였다. 노란색 염색 시약이 회 색으로, 흰색 시료가 검은색으로 변하면 염색이 완료된 것이 다. 이 시료를 면도날을 사용하여 상온 초박절편기의 고정홀 더에 들어갈 수 있을 정도의 크기와 두께로 잘라낸 다음 동 결 초박절편기와 같은 방법으로 시편을 제작하였다(Fig. 2e).

상기와 같이 동결 초박절편기와 상온 초박절편기를 사용 하여 준비된 시편을 EF-TEM (EM912 $\Omega$, Carl Zeiss, Germany)을 이용하여 비교 분석하였다. 동결 초박절편기로 제 작한 시편의 경우에는, 냉각기능을 활용했음에도 불구하고
이종 재료에 대한 경화정도 차이를 극복하지 못하고, 블록을 자를 때 절편이 많이 갈라지고 부서져 정상적인 절편을 획 득하는 것이 매우 어려웠다(Fig. 3a). 또한 반도전 전극층과 절연층의 계면의 구조형태를 관찰한 결과 균열이 생겨 계면 이 명확하게 관찰할 수 없었다(Fig. 3b). 이에 더하여 염색이 최적화 되지 않고, 절편자체에 동일한 조건으로 염색이 수행 되지 않아 오히려 염색약에 의해 오염이 발생되었음을 알 수 있다(Fig. 3c). 결과적으로 Fig. 3b와 3c의 TEM 영상에서 와 같이 시편의 염색과정을 거쳤지만 영상대비가 매우 좋지 않아 절연층 내의 라멜라 조직의 분포 분석이 불가능하여 시료의 특성 평가에 어려움이 발생하였다.

반면 상온 초박절편기로 제작한 시편의 경우에는 동결 초 박절편기로 제작한 절편에 비해 균열이 적고 균일한 절편을 

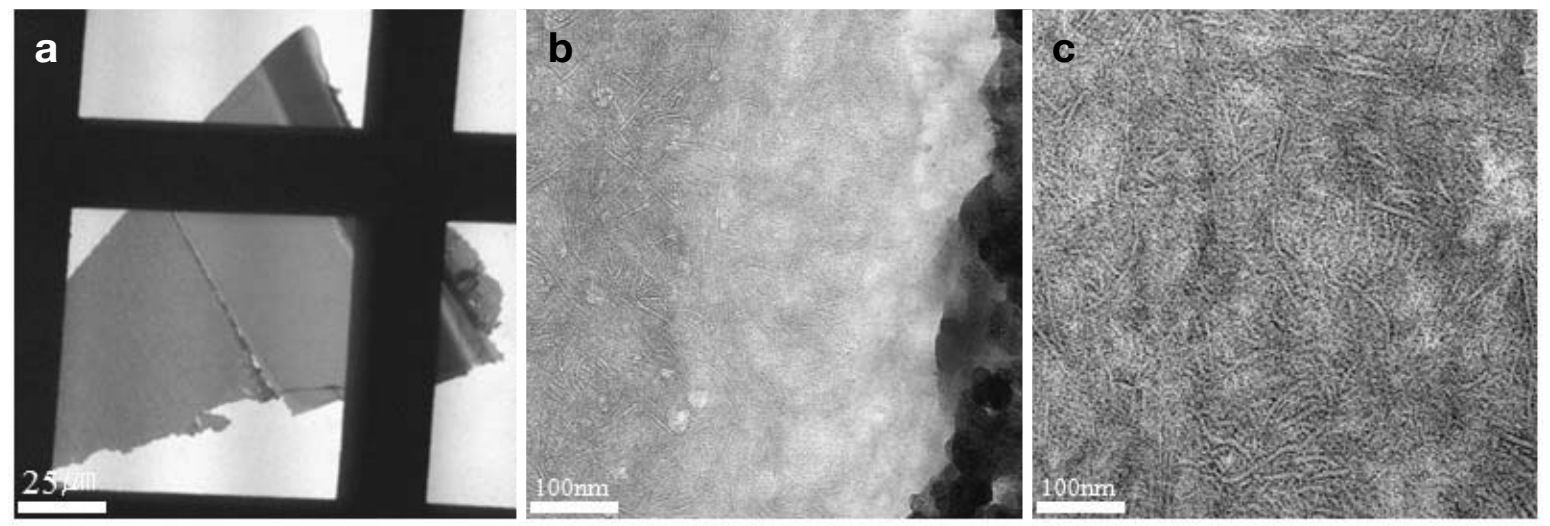

Fig. 4. TEM images of specimen produced by ultramicrotomy; (a) overall appearance of a section, (b) interface between semi-conducting and XLPE insulating material, (c) lamellar structure in XLPE insulating material.

얻을 수 있었다(Fig 4a). 또한 반도전 전극층과 절연층의 계 면의 사진(Fig. $4 \mathrm{~b})$ 을 보면 두 층은 전자밀도의 차이로 구분 되어 계면의 형태적 구분이 비교적 용이하여 두 층의 구조 를 정확하게 확인할 수 있었다. 특히 라멜라 조직의 고배율 사진(Fig. 4c)을 보면 라멜라 조직의 가장자리 부분이 잘 염 색되어 있어 라멜라 분포에 대한 분석이 가능하였으며, 또 한 정확한 라멜라 구조에 대한 정보도 얻을 수 있었다. 이로 인해 절연물질로 사용하고 있는 가교 폴리에틸렌의 경우, 정 확한 라멜라 분포와 구조 분석을 통해 라멜라 조직의 밀도가 높을수록 계면에 형성된 탄소 사슬 군집체가 가속전자에 대 한 장벽 역할을 하기 때문에 절연 파괴 특성이 향상된다는 사실을 규명할 수 있었다. 이러한 상온 초박절편기를 이용한 시편 제작법은 시편 제작에 앞서 선행된 염색의 조건에 따

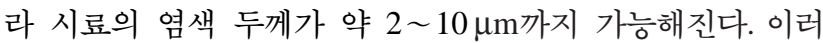
한 벌크 시료에 대한 연속 절편의 획득이 가능하기 때문에 시료의 깊이에 따라 적절한 염색이 이루어진 시편영역을 확 보하는데 유리할 수 있어, 동결 초박절편기를 이용한 시편 제 작과 달리 비용과 시간적인 면에서 상당히 유용할 수 있다.

초박절편기를 이용하여 TEM 시편 제작에 대한 연구는 다 양하게 시도되었고 대부분의 유기재료의 실험은 분석에 앞 서 연구내용을 정확하게 이해하는 것이 선행되고 있지만, 성 공적이고 보다 유용한 시료제작을 위해서는 장비와 재료의 물성을 숙지하여야 하며, 다양한 방법의 고려 및 시도가 필 요하다. 본 연구 결과와 같이 연성 이종 재료인 가교 폴리에 틸렌의 경우에는 동결 초박절편기 없이 적절한 염색 조건을 찾아 시료에 경화성을 부여한 후 상온 초박절편기로 작업하 여 TEM 시편을 만들 수 있음을 확인하였다. 따라서 본 실험 에서 사용한 시료 이외에도 다양한 연성 이종 재료로 구성 된 시료의 TEM 시편제작에 본 방법이 매우 효과적으로 응 용될 수 있고, 새로운 시편제작 방법 개발의 기초로 활용 될 수 있으리라 기대한다.

\section{참 고 문 헌}

Ayache J, Luc B, Jacqueline B, Gabrielle E, Daniéle L: Sample preparation handbook for transmission electron microscopy. Springer, New York, pp. 201-228, 2009.

Bozzola JJ and Russell LD: Electron Microscopy. Jones \& Bartlett Learning, Boston, pp. 72-82, 1992.

Chou TM, Prayoonthong P, Aitouchen A, Libera M: Nanoscale artifacts in $\mathrm{RuO}_{4}$-stained poly(styrene). Polymer 43(7) : 20852088, 2002

Jeong KU: Polymer structure analysis utilizing TEM and SAED. Polymer Science and Technology 20(2) : 180-185, 2009. (Korean)

Kato K: The osmium tetroxide procedure for light and electron microscopy of ABS plastics. Polymer Engineering and Science 7(1) : 38-39, 1967.

Okamoto T, Ishida M: Growth of Lamellar at the Semicon-Interface in XLPE Power Cables. 4th International Conference on Properties and Application of Dielectric materials, p. 455-458, Brisbane, Austrailia, 1994.

Sawyer LC, Grubb DT, Meyers GF: Polymer Microscopy. Champman and Hall, New York, pp. 130-247, 2008.

Shim SI, Cho DH, Youn BH: The microstructural analysis of XLPE insulation for power cable. International Conference on Electrical Engineering 2004, p. 380-383, Sapporo, Japan, 2004.

Vitali R, Montani E: Ruthenium tetroxide as a staining agent for unsaturated and saturated polymers. Polymer 21(10) : 1220-1222, 1980.

Yoo TJ: Insulation materials for power cable. Polymer Science and Technology 9(5) : 381-388, 1998. (Korean)

Youn BH, Cho DH, Shim SI: Improvement of breakdown strength by additives and curing conditions on XLPE insulation for power cable. IEEE transactions on Dielectrics and Electrical Insulation, p. 347-350, New Jersey, USA, 2004. 